\title{
Counsellors' Personal Quality in Public Senior High School
}

\author{
Zakki Nurul Amin \\ Department of Guidance and Counselling \\ Faculty of Education, Universitas Negeri Semarang \\ Semarang, Indonesia \\ zakki.nurul.amin@mail.unnes.ac.id \\ Mulawarman \\ Department of Guidance and Counselling \\ Faculty of Education, Universitas Negeri Semarang \\ Semarang, Indonesia
}

\author{
Edwindha Prafitra Nugraheni \\ Department of Guidance and Counselling \\ Faculty of Education, Universitas Negeri Semarang \\ Semarang, Indonesia
}

Carti

Department of Guidance and Counselling

Faculty of Education, Universitas Negeri Semarang Semarang, Indonesia

\begin{abstract}
Counsellors' personal quality is an important factor that supports the effectiveness of the school counselling services. The purpose of this study is to describe the counsellors' personal quality from educational qualification, gender, and working experience. The counsellors' personal quality scale was administered to 24 teachers from six schools in Semarang. Data were analyzed using descriptive statistics, non-parametric statistics Mann Whitney U Test and Kruskal-Wallis Test. The results showed that, in general, school counsellor had medium level of personal quality. There were no significant different of counsellors' personal quality in educational qualification, gender, and working experience. These findings have implication for developing school counsellor education program which currently only focus on intervention strategies. The program should also focus on counsellors' personal quality development. Also required personal and professional development design for school counselors to avoid burnout and stagnation in the work.
\end{abstract}

Keywords - personal quality; counsellor

\section{INTRODUCTION}

Many people consider counselling to be part science and part art. Successfully counselling clients through difficult times requires a combination of interpersonal skills, sufficient knowledge about the issues involved, and a host of personal attributes [1, 2]. This combination has made it difficult for researchers to completely understand what makes counselling effective. But, Rogers [3] states that personal attributes in an effective counselor become a major factor that supports the effectiveness of counselling.

McLeod [1] explain that counsellors' personal quality as one part of the skill of the effective counselor, understood as all the necessary personal characteristics counselors and support the effectiveness of counselling. Counselor's personal quality constructs about the qualities of the ideal counselor. Research has found that an effective counselor showed a positive attitude to clients $[4,5,6]$. Effective counsellors also show the ability to appreciate the client, to consider the extra-therapeutic issues related to effectiveness, to form an alliance, and to conceptualize counselling in productive ways in order to raise the client's competence.

Hershenson and Power as cited in Marini and Stebnicki [7] explain that counsellors help clients in reaching 'their optimal level of psychosocial functioning through resolving negative patterns, prevention, rehabilitation, and improving quality of life. They help all students in the areas of academic achievement; personal/social development and career development, ensuring today's students become the productive, well-adjusted adults of tomorrow [8, 9]. Therefore effective counsellors also show the ability to appreciate the client, to consider the extra-therapeutic issues related to effectiveness, to form an alliance, and to conceptualize counselling in productive ways in order to raise the client's sense of competence.

An effective counsellor has a personal quality that can be modeled to the students and the clients. Personal qualities become an important factor in counseling as a determining factor for the achievement of an effective counseling, besides the factors knowledge of the behavior and skills of counselling [10]. Counsellor's personal quality raises therapeutic alliance that improves effectiveness of counselling process. Norcross as cited in Bertolino \& O'Hanlon [11] explained that therapeutic alliance between counsellor and client influence until $30 \%$ against change client attitude, higher than the implementation of the model or counselling techniques. Likewise, some researchers put forward that therapeutic relationship [12, 13] and therapeutic alliance [14] provide a considerable contribution in terms of counselling's success. Corey [15] revealed that therapeutic alliance raises from therapist therapeutic personal are strongly and consistently become the main factor that support the purpose of client. Counsellor therapeutic personality can facilitate the changes of client therapeutic personality.

There are a number of key personal qualities that should be possessed by a counselor and psychotherapist, and that will make them therapeutic relationship with clients more effectively. Generally there are 3 conditions needed to facilitate the therapeutic personality changes that are 
congruence/genuineness, unconditional positive regard, and accurate emphatic understanding $[15,16]$. Congruence demonstrated through to the genuine therapist, does not pretend, sincere, openness, and consciously presented himself during the counselling process. The unconditional positive regard indicated by the behavior of the warmth, attention, acceptance and positive respect without conditions. While accurate emphatic understanding is shown when counsellors are able to align themselves on the internal frame of reference that clients felt.

Until recently, profile of the counselor's personal quality as effective therapist only little convincing evidence to answer this question, but that deficit has changed in the past few years [17]. Profile of the counselor's personal quality as effective therapist has been defined based on theory, policy, and research evidence, can guide therapists toward continual improvement. Brammer [18] describes counselor qualifications of individuals and professionals. Counsellors as an individual indicated by the attributes of personality such as care to others, responsible, warm, and empathy. Wamplod [19] explained that effective therapists have a sophisticated set of interpersonal skills, including verbal fluency, interpersonal perception, affective modulation and expressiveness, warmth and acceptance, empathy. While personality competencies according to Indonesia education minister regulation number 27 in 2008 about standard academic qualification and competency counsellors that is: (1) believe and fear to God Almighty, (2) respect the values of humanity, individuality and freedom of choice, (3) shows integrity and strong personality stability, (4) displays the high quality performance.

Everything about profession and personality counsellors related with public trust toward counselling services. To date, however, there is limited evidence on the effectiveness of school counselors [20]. The phenomenon, counsellor qualifications is not satisfy and still got a lot of criticism from the students, teachers, and the general public [21, 22]. Indicated with unfriendly attitude, less flexible, and not to be trusted. It has an impact on the low confidence of stakeholders on the guidance and counselling services in schools.

Besides the phenomenon, the study of the counselors' personal qualities can also be seen from education qualification [23] and personal attributes [24, 25] that influence personal characteristics, such as gender, age and working experience, which until now the results are still overlapping and inconsistent. Therefore this research purpose to describe counsellors' personal quality in general, based on education qualification, gender, and working experience. These findings have implication for developing school counsellor education program.

\section{MethodS}

\section{A. Procedure and participant}

The current research collected data based on survey method and by using data collection techniques and questionnaire to understand and describe the counsellors' personal quality. The subjects in this research were 24 counsellors from 6 high schools in the Semarang City (7 man and 17 woman).

\section{B. Instrument}

The instrument used in this research is the counsellors' personal quality scale that consists of aspects (1) believe and fear to God Almighty, (2) respect the values of humanity, individuality and freedom of choice, (3) shows integrity and strong personality stability, (4) displays the high quality performance. The validity of the research instrument using the construct validity and has been validated by professional judgment with product moment score $(0.420-0.788)$. In order to determine the reliability coefficient Cronbach Alpha formula is used. The calculated reliability was $r=0.886$ which was acceptable.

\section{Data analysis}

Data were analyzed using descriptive statistics, nonparametric statistics Mann Whitney U Test and Kruskal-Wallis Test. Descriptive statistics used to know a description of the counsellors personal quality in general, statistics nonparametric Mann Whitney $U$ test used to determine counsellors' personal quality based on educational qualification differences (guidance and counselling program \& nonguidance and counselling program) and gender differences (men and women), while Kruskal-Wallis Test used to comparison counsellors' personal quality in working experience (0-15 years, 16-25 years, and more than 25 years).

\section{RESULT AND DISCUSSION}

\section{A. Descriptive data}

Based on the research, counsellors' personal quality had medium level with mean $M=78.13$ (see table 1 ). It means the majority of counsellors in high school had medium level, indicates that the counsellor feel the attitude, quality, and personal competencies was appropriate with the ideal criteria must be owned by a counsellor. In other words personal quality counsellors were considered sufficient reflect the counsellor personality competencies. As much as 6 counsellors from the total 24 counsellors or $25 \%$ of the total respondents had high level counsellors' personal quality, while the other 19 counsellor or $75 \%$ had medium level.

Furthermore on every counsellor's personal quality aspect, the highest aspect is "believe and fear to God Almighty $(M=$ 83.61)". While the lowest aspect located on "displays the high quality performance $(M=65.00)$ " ( see table 2$)$.

\section{B. Counsellors' personal quality reviewed from education qualification, gender, and working experience}

The first hypothesis proposed to know the counsellors' personal quality reviewed from the education qualification. Analysis using Mean Whitney U Test to see differences between the graduate counsellors from guidance and counselling (GC) program with non-graduates GC program. The results showed that no significant differences between counsellors that graduate from GC program non-GC program $(\mathrm{Z}=-0.675, \mathrm{p}>0.05)$.

The second hypothesis proposed to know the counsellors' personal quality reviewed from gender differences (male counsellor and women). Although the woman counsellor had 
higher average than male, but in statistics using Mean Whitney $\mathrm{U}$ Test there is no significant differences counsellors' personal quality between man and woman $(\mathrm{Z}$ score $=-1.190, \mathrm{p}>0.05)$.

While the third hypothesis proposed to know the counsellors' personal quality reviewed from the working experience to see the level of differences counsellors who have worked for 0-15 years, 16-25 years, and above 25 years. The highest average obtained by counsellors with working experience for $0-15$ years $(M=83.67)$, followed by counsellors with working experience for $16-25$ years $(M=77.71)$, and the lowest is counsellors with working experience above 25 years $(M=75.36)$. Even though the statistics analysis using KruskalWallis Test suggest there is no significant differences counsellor personal quality reviewed from the working experience $\left(\chi^{2}(2)=4.638, \mathrm{p}>0.05\right)$.

TABle 1. DATA DESCRIPTION COUNSELlORS' PERSONAL QUALITY

\begin{tabular}{|l|l|l|l|}
\hline Factor & Level & Mean & SD \\
\hline Educational Graduate & GC program & 78.00 & 8.997 \\
\hline & Non-GC program & 78.50 & 5.026 \\
\hline Gender & Male & 74.57 & 9.181 \\
\hline & Woman & 79.59 & 7.425 \\
\hline Working Experience & 0-15 years & 83.67 & 7.737 \\
\hline & $16-25$ years & 77.71 & 4.680 \\
\hline & $>25$ years & 75.36 & 9.014 \\
\hline Total & 78.13 & 8.110 \\
\hline
\end{tabular}

TABLe 2. Counsellors' Personal Quality ASPeCt

\begin{tabular}{|l|l|l|}
\hline Aspect & Mean & Criteria \\
\hline Believe and fear to God Almighty & 83.61 & Medium \\
\hline Respect the values of humanity & 79.91 & Medium \\
\hline Shows integrity and strong personality stability & 74.58 & Medium \\
\hline Displays the high quality performance & 65.00 & Low \\
\hline
\end{tabular}

\section{Discussion}

Counsellor personal quality has an important bearing on therapeutic outcomes [10]. Some results of the study showed that the counsellor personal quality became the determining factor for an effective counselling, in addition the factors of knowledge about the behavior dynamics and therapeutic skills or counselling [26, 27]. The effectiveness of guidance and counselling services is located on the competencies as a counsellor to being a helper, includes a combination of academic knowledge, personal quality and helping skills [28]. Wosket [29] has suggested a natural correlation between the personal characteristics of the counsellor and the way their style and approach develops. Counsellors are required to have a personality is able to support the effectiveness of the counselling.

An effective counsellor is a counsellor who can remodel personal quality and also can understand us, client, the purpose and the process of counselling [27]. Some of literature differentiates personal quality that reviewed from the counsellor background, for example educational background, gender, and working experience [28]. However other literature explains that effective counsellors typically have a profound, genuine and early draw to the field [3].
Counsellor education background in this study differentiated between the graduate counsellor from guidance and counselling (GC) program with non-graduates GC program. But based on the results there is not found significant differences between counsellors graduates from GC program with non-GC program, so it can be understood that the counsellors' personal quality is not enough viewed just from the education background and training professionals. In line with the opinion Jennings and Skovholt [30] that education is not a major determinant in the development of counsellors' personal quality.

The frequent use of professional qualification, professional backgrounds, and professionalism and experience features implies that participants may have attributed the professional qualification to the education and experience dimensions. However, according to Laireiter and Botermans cited in Sanberk [25], education alone does not guarantee the qualification of a counselor. The education needs to fulfill the required standards and needs to be associated with a specific problem domain. Education will be helpful for effective counselors only if all these requirements are fulfilled.

Though education and professional training are necessary to begin a career in counselling, an individual's personal characteristics play a crucial role in achieving success in this profession. Komalasari [31] suggest that counsellors' personal quality is the comprehensive aspect, regarding all aspects of personality, which are important and determine the counsellor effectiveness not merely compared with education or training acquired.

In the second hypothesis, gender differences between men and women often become a sensitive issue in several culture [32]. In generally gender differences used to identify the difference between men and women in terms of social and cultural. Significant personality differences have been found based on gender, Costa, Terracciano, and McCrae as cited in Noel, Trocchia, and Luckett [33] found women consistently report higher 'nurturing' aspects of neuroticism, agreeableness, warmth and openness to feelings, and men often report higher facets of 'extraversion', such as, assertiveness, dominance and openness to ideas.

However, this study found different results. This research found that there is no significant difference between the male counsellors with women in the personal quality. In line with these findings, Elliot [34] asserts that the identity and roles gender cannot be the only reference, especially made discrimination for personal characteristics counsellors. Personal characteristics between men and women not different significantly, both of them have some of the same process to evaluate the situation based on the ethics that is believed by the individual [24].

While the relation with working experience, numerous authors have highlighted the significance of counsellors' experiences of the therapeutic relationship to their growth and development [23, 35]. Experience is one of the mostly used constructs in education. Experience often referred to being an effective counselor probably enables them to feel better. To perceive himself or herself as an unqualified counselor merely reflect the immediate situation. The possible reason for 
expressing experience so often is to reinforce self-belief about compensating for their deficiencies in the future. Yet, as Beutler cited in Sanberk [25] points out, time or rather age does not always guarantee experience. This research finds that counsellors with working experience $0-15$ years have a higher personal quality when compared with the counsellor who has working experience during 16-25 years, and above 25 years. But the result is not significantly different in statistic test.

Research on counsellor development suggests a close link between how counsellors manage challenges in the therapeutic relationship and their experiences of either growth or stagnation in their professional development [35]. Counselors experience a high level of job stress and professional burnout and those they have a low level of job satisfaction. Difficulties and troubles both in personal and professional life cause serious problems for the individual and the institution. As revealed in previous research, stagnation and burnout seems to negatively affect performance and productivity $[9,36,37]$.

The results showed that the sample had better developed the counsellor personal competencies; especially they needed more training in quality performance. Investigating the counselors specialized competencies acquired via education and in service training and also the need for further training [37]. They need various types of training including other forms of professional and personal development (e.g., supervision, peer support, self-awareness). Their perceived training needs included not only knowledge and skills related to guidance and counselling, but also life skills and personality. They demanded training in communication skills, personal skills and ways to deal with their own issues.

Competence in the area of personal beliefs and attitudes consists not only of having certain ways of seeing the world, but also of having accurate self-awareness regarding them. Clients may well possess quite different sets of beliefs and attitudes, and may even on occasion dispute the legitimacy of what they perceive to be the way the counsellor views things. To be able to handle these situations a counsellor needs to be able to stand back from her own philosophical position in order to let the client know she is capable of accepting his contrasting perspective. Many training courses, therefore, include work on 'values clarification', and this issue is also common in supervision.

As a consequence, become counselors who provide support services in schools need to make continuous improvement and development in terms of both professional and personal. Being a helper developed through a long process, begins with learning various theory, practice, and attempting to learn from practical experience. But not only knowledge and practices, it is important to understand the counsellors' personal quality become determine aspects that support the success of counselling services.

All the counsellors are not alike. They differ in various ways. Their personal characteristics, as well as, their personality differ quite substantially. Many of these people describe their experiences in different way that shows the uniqueness and specificity every person. A number of research organizations have tried to ascertain the personal qualities of a counsellor, which are essential to bring about therapeutic al transformation in another person. Effective counsellors demonstrate an attitude that human nature is so complex that they could never possibly stop learning in this field.

\section{CONCLUSION AND ACKNOWLEDGEMENT}

Present study finds that counsellors' personal quality in Semarang had medium level with $M=78.13$. There is no significant difference in counsellor's personal quality when reviewed from the educational graduates, gender, and working experience. A counsellor's own personal development must be in a continual process of development, growth and expansion. They must demonstrate an interest in self-awareness, selfcounselling, work/life balance, focus, goal setting and other complementary areas of self-knowledge. Through their own development a counsellor will also pick up additional understanding and knowledge, which they can effectively use to support a client during the counselling process.

Furthermore, this study was funded by the Universitas Negeri Semarang research Foundation. The authors sincerely thank the foundation and all respondent who participated in this research.

\section{LIMITATION AND IMPLICATIONS}

However, current study has some limitations. First, the number of respondents that relatively small $(N=24)$. Therefore, further study can increase the number of respondents that more attention with the spread of the respondents. Therefore, further study could increase the number of respondents to strengthen generalization. Second, the counsellors' personal quality scale used in this research is mainly based on personal competence counsellors are present on the minister regulation. Further study can also develop counsellors' personal quality scale by integrating and balancing with basic theory in order to comprehensively reveal counsellors' personal quality. In addition further research can combine quantitative and qualitative data to refine the findings. Finally, in this study counsellors' personal quality only reviewed from demographics backgrounds that are education graduates, gender, and working experience. Further study can also review counselors' personal quality from other related components such as ethnic differences, age difference, anxiety, motivation and other personality components.

There are two practice implications from present findings. First, need to development program can increase counsellors' personal quality in Semarang, especially related to the aspects displays the high quality performance. In service training and supervision program needed by counselors to maintain and improve the competence, including the personal competence. Courses and training is required and is believed to be more effective to develop insights when they are based on evidence. Additionally, when counselor candidates are provided with more role models, they will develop a better understanding of what type of counselors they want to become.

Second, to counsellor educator institutions, understanding the complex and unique counsellors' personal quality and it important factor that support the effectiveness of the school 
counselling services, therefore the curriculum need to facilitate development of counsellors' personal quality aspect. curriculum developed at universities for candidate counselors not only focuses on understanding the theory and intervention strategies, but also need to focus on the study and practice of personal development. Need for experiences directly related to the counselors' personal qualities, such as empathy training, emotional control, and other personal soft skills.

\section{REFERENCES}

[1] J. McLeod, An introduction to counselling, 4rd ed., New York: McGraw-Hill Open University Press, 2009, pp. 612-613.

[2] R. P. Bedi, M. D. Davis, and M. J. Arvay, "The client's perspective on forming a counselling alliance and implications for research on counsellor training," Canadian Journal of Counselling, 2005, Vol. 39:2, pp. 71-85.

[3] C. Rogers, On becoming a person: A therapist's view of psychotherapy, London: Constable, 1961, pp. 199-201.

[4] K. B. Bernes, "The elements of effective counselling," The national consultation on career development, 2005.

[5] S. L. Garfield, "The therapist as neglected variable in psychotherapy research," Journal Clinical Psychology: Science and Practice, 1997, Vol 4, pp. 40-43.

[6] J. Okiishi, M.J. Lambert, S.L. Nielsen, \& B.M. Ogles, "An empirical analysis of therapis effect," Journal Clinical Psychology \& Psychotherapy, 2003, Vol. 10 (6),pp. 361-373.

[7] I. Marini and M.A Stebnicki, "The professional counsellor's desk reference," Springer, 2009.

[8] H. Torunoğlu and D. Gençtanırım, "The perceptions of school counsellors about the counselling and guidance programs of vocational high schools," Procedia - Social and Behavioral Sciences, 2015, Vol. 174, pp. $368-376$.

[9] F.Y. Sahin, "School counsellors' assessment of the psychological counselling and guidance services they offer at their schools," Procedia - Social and Behavioral Sciences, 2012, Vol 47, pp. 327 - 339 .

[10] S. Wilis. Konseling Indvidual Teori dan Praktek. Bandung: Alfabeta, 2004, pp. 79.

[11] B. Bertolino and B. O'Hanlon. Collaborative, competency-based: counselling and psychotherapy, Boston. Allyn and Bacon. 2002, pp. 1517.

[12] S.A. Baldwin, B.E. Wampold, and Z.E. Imel, " Untangling the allianceoutcome correlation: Exploring the relative importance of therapist and patient variability in the alliance," Journal of Consulting and Clinical Psychology, 2007, Vol 75, pp. 842-852.

[13] D.E. Orlinsky, K. Grawe, and B.K. Parks. "Process and Outcome in psychotherapy" Noch einmal in A.E. Bergin and S.L. Garfield (Eds), Handbook of psychotherapy and behavior change, New York: Wiley, 1994, pp. 280-329.

[14] M. E. Emmerling an W. J. Whelton, "Stages of change and the working alliance in psychotherapy," Psychotherapy Research, 2009, Vol 19(6), pp. 687-698.

[15] G. Corey, Theory and practice counselling and psychotherapy, United States: Brook/Cole, 2013, pp. 18-19.

[16] E. Neukrug, The world of the counsellor: An introduction to the counselling professional, United States: Thomson Brooks/Cole, 2012, pp. 20.
[17] L. Sperry, "Therapist effects and spiritually oriented psychotherapy," Open Theology, 2016, Vol 2, pp. 286-295.

[18] L. M Brammer, “ The helping relathionsip process and skills.” New Jersey: Prentice Hall, 1979.

[19] B. Wampold. Qualities and actions of effective therapists. Washington, DC: American Psychological Association, 2011.

[20] S.E. Carrell and M. Hoekstra, "Are school counselors an effective education input?" Journal Economics Letters, 2014, Vol 125, pp. 66-69.

[21] M. Alavi, N. Boujarian, and M.T. Ninggal, "The challenges of high school counsellors in work place", Procedia - Social and Behavioral Sciences, 2012, pp. $4786-4792$.

[22] R. Khansa, "Teachers' Perceptions toward school counselors in selected private schools in Lebanon," Procedia - Social and Behavioral Sciences, 2015 , Vol 185 , pp. $381-387$.

[23] J.M. McGlothlin and L.G. Miller, "Hiring effective secondary school counselors," NASSP Bulletin, 2008, Vol. 92 no. 1, pp. 61-72.

[24] S. Lam, S. Tracz, and C. Lucey, "Age, gender, and ethnicity of counsellor traineesand corresponding counselling self-efficacy: Research findings and implications for counsellor educators," International Journal Adv Counselling: Springer, 2012, Vol. 35, pp. 172-187.

[25] I. Sanberk, "Investigation and classification of personal constructs representing ideal counselor from insider perspective,", Journal of Education and Training Studies, 2016, Vol. 4 no. 8, pp. 56-64.

[26] R. L. Gibson and M. H. Mitchell, "Introduction to counselling and guidance," London: Prentice Hall, 2003.

[27] S. Bhargava and S. Sriram, "Counsellor characteristics and the counselling experience", Springer Science+Business Media Singapore, 2016, pp. 13-33.

[28] M.E Cavanagh, “The counselling experience," California: Wadsworth Inc, 1982, pp. 73-94.

[29] V. Wosket, “Therapeutic use of self," London: Taylor and Francis, 2002.

[30] L. Jennings and T.M. Skovholt, "The cognitive, emotional, and relational characteristics of master therapists," Journal of Counseling Psychology, 1999, Vol.46, pp. 3-11.

[31] G. Komalasari, E. Wahyuni and Karsih, Teori dan teknik konseling, Jakarta Indonesia: PT Indeks, 2011.

[32] C. Barker, Cultural studies, Yogyakarta Indonesia:Kreasi Wacana, 2010.

[33] N.M. Noel, P. Trocchia, and M. Luckett, "A predictive psychometric model to identify personality and gender differences of college majors, " The International Journal of Management Education, 2016, Vol 14, pp. 240-247.

[34] G.R. Elliott, “ When values and ethics conflict: The counsellor's role and responsibility," Alabama Counselling Association Journal, 2011. Volume 37 no. 1, pp. 39-45.

[35] M. H Ronnestad and T.M. Skovholt, "The journey of the counsellor and therapist: Research findings and perspectives on professional development," Journal of Career Development, 2003, Vol 30, pp. 5-44.

[36] A.D. Rayle, "Do school counselors matter? Mattering as a moderator between job stress and job satisfaction," Professional School Counselling, 2006, Vol. 9 (3), pp. 206-215.

[37] K. Kounenoua, G. Koumoundouroua, and E.M. Botsaria, "Greek school career Counselors competencies and burnout Syndrome," Procedia Social and Behavioral Sciences, 2010, Vol 2, pp. 1890-1895. 